\title{
A Novel Multiobjective Programming Model for Coping with Supplier Selection Disruption Risks under Mixed Uncertainties
}

\author{
Ying Li, ${ }^{1}$ Jing Han, ${ }^{2,3}$ and Liming Yao ${ }^{1}$ \\ ${ }^{1}$ Business School, Sichuan University, Chengdu 610064, China \\ ${ }^{2}$ International Business School, Shaanxi Normal University, Xi'an 710119, China \\ ${ }^{3}$ School of Management, Xian Jiaotong University, Xian 710049, China
}

Correspondence should be addressed to Liming Yao; lmyao@scu.edu.cn

Received 15 June 2016; Accepted 29 August 2016

Academic Editor: Xiaofeng Xu

Copyright (C) 2016 Ying Li et al. This is an open access article distributed under the Creative Commons Attribution License, which permits unrestricted use, distribution, and reproduction in any medium, provided the original work is properly cited.

\begin{abstract}
Supply chain has become more and more vulnerable to disruption since it is suffering widespread risk issues from inside or outside. Higher uncertainties in the supplier selection problem have gone beyond the traditional cost minimization concern. These uncertainties are related to an ever increasing product variety, more demanding customers, and a highly interconnected distribution network. This paper focuses on the supplier selection problem with disruption risks and mixed uncertainties. A novel multiobjective optimization model with mixed uncertain coefficients is developed, which maximizes the total profits and minimizes the percentage of items delivered late, percentage of items rejected, and total loss cost due to supplier dysfunction. Meanwhile, we also consider the customer demand to be a random fuzzy variable and the unit purchase cost to be a fuzzy variable. By examining a numerical example, we found that the confidence level and demand of customers have impact on the quantities purchased by customers from suppliers although the distribution of suppliers will not change. The cost, quality, and service also influence the selection of suppliers. The superevents have little influence on the distribution of supplier selection; however, when unique event occurs, the distribution of supplier selection will change.
\end{abstract}

\section{Introduction}

Risks and uncertainties existing in supply chain increase the analytically complexity, which usually leads to the huge loss or supply chain disruption. Besides the profit, delivered late, and percentage of items rejected, risk and uncertainty management is of key importance to reduce the supply chain vulnerability. There is a common consensus that many sources of threats result in a sharp increase of supplier selection risk in a global supply chain system. For example, the occurrence of disasters and political conflicts could create supply chain disruptions. Some inherent uncertain factors in traditional supply chain such as high supply and demand uncertainties during the operating process make it hard to avoid the risk in supply chain.

Supply chain risks are usually divided into two categories: (i) disruption risks and (ii) operational risks [1]. Focusing on the supplier selection problem, there is no doubt that disruption risk management is one of the critical activities for firms to ensure their effectiveness and competitiveness and achieve the objectives of the whole supply chain. Berger et al. [2] introduced a decision tree model to consider supplier selection under risk and uncertainty in order to identify the optimal number of suppliers in the supply chain. In their work, two types of risks are discussed: catastrophic super events that affect all suppliers and unique events which affect a single supplier. Sawik [3] proposed a stochastic mixed-integer programming approach to cope with joint supplier selection and scheduling problem under disruption risks. Sawik [4] also addressed a fair optimization of cost and customer service level in the presence of supply chain disruption risks. Hamdi et al. [5] presented two integer programming models to determine the supplier selection and order allocation in the presence of disruption risk supplier. Torabi et al. [6] developed a biobjective mixed possibilistic, two-stage stochastic programming model to address supplier 
selection and order allocation problem to build the resilient supply base under operational and disruption risks. Fahimnia et al. [7] presented a systematic review of the quantitative and analytical models for managing supply chain risks and found that sustainability risk analysis is an emerging and fast evolving research topic. Heckmann et al. [8] studied the review of the definition, measure, and modeling of supply chain risks. Wiengarten et al. [9] explored the role of risk and risk management practices of supply chain integration and found that supplier integration is also effective in weak rule of law (i.e., high risk) environments. The above researches about supply chain risks concentrate on some general nodes of a supply chain but not a type of supply problems with special characteristics. In this paper, we employ three types of risk situation to measure the disruption risk of supplier selection problem: "superevents" such as terrorism or a widespread airline action that put all suppliers down; "unique event" uniquely associated with a particular supplier that puts it down during the supply cycle; and "semisuperevents" that affect a subset of all suppliers, but more than one and not all suppliers.

Higher uncertainties in the supplier selection problem have gone beyond the traditional cost minimization concern. These uncertainties are related to an ever increasing product variety, more demanding customers, and a highly interconnected distribution network. Research on uncertainties in supply chain systems is a timely and important topic nowadays in both academia and industry, and some quantitative models have been gradually developed [1012]. Memon et al. [13] claimed that supplier selection is highly associated with recognitive and stochastic uncertainties and depends on large amount of domain knowledge. Amorim et al. [14] proposed an integrated framework to determine the supplier in the processed food industry under uncertainty. Moghaddam [15] developed a fuzzy multiobjective mathematical model for decision making of supplier selection under supply and demand uncertainty. Azaron et al. [16] developed a multiobjective stochastic programming approach for minimizing the financial risk or the probability of not meeting a certain budget in a supply chain system under uncertainty. Dickson [17] initially stated five criteria of supplier selection including quality, delivery, performance history, warranty policy, and supplier's production capacity. Some recent researches identified that as quality, cost, and delivery performance history [18], or cost, quality, and time response [19]. Gaballa [20] developed a single-objective, mixed-integer programming model to minimize the total cost. Ghodsypour and O'Brien [21] took the price, storage, and order cost as well as transportation into consideration and developed a mixed-integer nonlinear programming model for minimizing total cost. However, in the practical problems, most of the input parameters are inaccurate, or some of the factors are uncertain. The uncertainty usually results in the widespread risk issues within or external to the supplier selection of a supply chain system. Aghai et al. [22] developed a fuzzy multiobjective programming model containing quantitative and qualitative risk factors as well as quantity discount to propose supplier selection. In their model, late items, rejected items, environment conditions, and vendor rate are set as qualitative factors (fuzzy), and just unit cost is modeled as quantitative factor. Wu et al. [23] considered both qualitative and quantitative risk factors including vendor ratings, cost, quality, and logistics, which were formulated by some fuzzy data, to decide on supplier selection.

In contrast to much of the extant literature, the contribution and innovation of this paper can be summarized as follows:

(i) Three types of risk events for supplier selection in a supply chain system are introduced: (i) the superevents; (ii) when all suppliers close down during the supply cycle; and (iii) when some, but not all the suppliers, close down.

(ii) We explore a mixed-uncertain situation for supplier selection, in which the customer demand is considered to be a random fuzzy variable and customers' purchase cost, percentage of items being late, and percentage of rejected items are considered to be fuzzy variables.

(iii) A novel multiobjective programming with mixed uncertain coefficients is developed for coping with the supplier selection disruption risk. The proposed model simultaneously maximizes the total profits and minimizes the percentage of items delivered late, percentage of items rejected, and the total loss cost due to supplier dysfunction.

The structure of this paper is as follows: after introducing three types of risk events for supplier selection in a supply chain system, a novel multiobjective programming with mixed uncertain coefficients is developed for coping with the supply chain risk in Section 2; Section 3 presents a comprised solution-based GA to solve the proposed multiobjective programming model; Section 4 examines a numerical example to show the effectiveness of the proposed model; and Section 5 draws the conclusions of the study.

\section{Supply Chain Risk Modelling}

2.1. Problem Statement and Notations. Supply chain risk management is usually discussed from the four perspectives: (i) disruption risk management, (ii) operational risk control, (iii) disaster and emergency management, and (iv) supply chain service risk analysis. In this study, a supplier selection problem in supply chain systems with disruption risks and uncertainties is considered. In the present problem, three types of risk situations are considered: "superevents" such as terrorism or a widespread airline action that put all suppliers down; "unique event" uniquely associated with a particular supplier that puts it down during the supply cycle; and "semisuperevents" that affect a subset of all suppliers, but more than one and not all suppliers. Following that, a total loss cost objective due to supplier dysfunction is considered in the supplier selection problem. Besides, three traditional objectives including maximizing the total profits and minimizing the percentage of items delivered late and 
percentage of items rejected are also considered to optimize the selection of suppliers.

In addition to the above complications, there is a great level of inherent uncertainty involved with customers' demand, customers' purchase cost, percentage of items being late, and percentage of rejected items that should be addressed in the decision making context in supplier selection problems. Customers' demand is usually estimated by large amount of historical data and expert's assessment, so it is formulated by a random fuzzy variable. Customers' purchase cost, percentage of items being late, and percentage of rejected items usually depend on large amount of domain knowledge where expert's assessment plays an important role when decision makers have lack of knowledge or small availability of information for different set of suppliers. Therefore, they are assumed as fuzzy variables which are widely used to handle the recognitive uncertainty.

To model and solve the above complex supplier selection problem with disruption risks and mixed uncertainties, a multiobjective mathematical model with mixed uncertain coefficients is formulated by using the following notations for sets, indices, decision variables, and parameters.

Indices

$i$ : index for the customer

$j$ : index for the supplier

\section{Parameters}

$n_{i}$ : number of candidate suppliers required by the $i$ th customer

$s_{i}$ : unit selling price for the $i$ th customer

$c_{i j}$ : unit purchase cost from supplier $j$ by the $i$ th customer

$\lambda_{i j}$ : percentage of items being late from supplier $j$ to the $i$ th customer

$k$ : unit cost of items being late

$\tau_{i j}$ : percentage of rejected items from supplier $j$

$l$ : unit cost of rejected items

$D_{i}$ : demand for item over planning period from the $i$ th customer

$u_{i j}$ : maximum amount for the item to be given to supplier $j$ by the $i$ th customer

$w_{i j}$ : maximum order quantity from supplier $j$ by the $i$ th customer

$\pi_{0}$ : probability of one of the superevents occurring in a supply cycle

$\pi_{j}$ : probability of the unique event occurring in a supply cycle for supplier $j$

$I_{0}$ : random indicator associated with the superevents

$I_{j}$ : random indicator associated with the unique event for supplier $j$

\section{Decision Variables}

$x_{i j}$ : quantity purchased by the $i$ th customer from supplier $j$
2.2. Modeling. Many traditional models due to the lack of consideration of various demand risks from many different customers usually consider the following objectives and constraints [24]:

Objective 1: maximize the expected value of total profits comprised by income and costs

Objective 2: maximize the utility of the number of or rejected items

Objective 3: maximize the utility of the number of late deliveries

Constraint 4: ensure that the quantity demand is met

Constraint 5: ensure that the customer's proposed business to the vendor is not exceeded

Constraint 6: establish minimum business for selected vendors

Constraint 7: ensure that there are no negative orders.

A deterministic multiobjective programming model (LMOP) for the supplier selection is presented as follows:

$$
\begin{array}{cl}
\left.\max \quad f_{1}\left(x_{i j}\right)=\sum_{i=1}^{m} D_{i} s_{i}-\sum_{i=1}^{m} \sum_{j=1}^{n_{i}} c_{i j} x_{i j} \quad \text { \{\#total profits }\right\} \\
\min \quad f_{2}\left(x_{i j}\right)=l \sum_{i=1}^{m} \sum_{j=1}^{n_{i}} \tau_{i j} x_{i j} \quad\{\# \text { rejected }\} \\
\min \quad f_{3}\left(x_{i j}\right)=k \sum_{i=1}^{m} \sum_{j=1}^{n_{i}} \lambda_{i j} x_{i j} \quad\{\# \text { late }\} \\
\text { subject to: } \quad \sum_{j=1}^{n_{i}} x_{i j} \geq D_{i}, \quad i=1, \ldots, m \\
x_{i j} \leq u_{i j}
\end{array}
$$

$\{\#$ upper business bound set for the purchased amount $\}, \forall i, j$

$$
x_{i j} \leq w_{i j}
$$

$\{\#$ upper order bound for the purchased amount $\}, \forall i, j$

$$
x_{i j} \geq 0 \text {, }
$$

where $j=1,2, \ldots, n$ represents the possible vendors selected for the $i$ th customer. The model LMOP (1) simultaneously maximizes the total profits $\left(f_{1}\left(x_{i j}\right)\right)$ and minimizes the percentage of items delivered late $\left(f_{2}\left(x_{i j}\right)\right)$ and percentage of items rejected $\left(f_{3}\left(x_{i j}\right)\right)$, while satisfying various constraints with respect to the order quantities.

When any of the above three types of risk situations takes place, the core company, that is, supplier partner, will suffer some loss. The event triggering the loss comes from three sources: (i) the superevents; (ii) when all suppliers close down during the supply cycle; and (iii) when some, but not all the suppliers, close down. We denote by $I_{0}$ and $I_{j}$ the indicator random variable associated with the former two risk situations, respectively. We use $J \in 1,2, \ldots, n_{i}$ and $\pi_{j}$ to denote the probability of the superevent occurring and unique event occurring for supplier $j$ during the supply cycle, respectively; that is, $\operatorname{probability}\left(I_{0}=1\right)=P$ and 
$\operatorname{probability}\left(I_{j}=1\right)=\pi_{j}$. We denote $L_{0 j}$ to be the unit financial loss due to either the superevent occurring on the $j$ th supplier or when all suppliers close down, and we denote by $L_{P}$ the unit financial loss when some, but not all suppliers, close down.

The first two cases result in the total loss $\left(x_{i j} L_{0 j}\right)$ and the last case results in partial loss $\left(x_{i j} L_{P}\right)$. Thus, the loss cost associated with each set of suppliers $n_{i}$ can be represented by

$$
\begin{aligned}
f(J) & \\
= & {\left[I_{0}+\left(1-I_{0}\right) \prod_{j \in J} I_{j}\right] \sum_{j \in J}\left(L_{0 j} x_{i j}\right) } \\
& +\left[1-\prod_{j \in J} I_{j}-\prod_{j \in J}\left(1-I_{j}\right)\right]\left(1-I_{0}\right) \sum_{j \in J}\left(L_{P} x_{i j}\right) .
\end{aligned}
$$

Choi et al. [1] argue that omission of "semisuperevents" loss greatly simplifies the computation while it does not materially affect the salient issues to be analyzed and discussed. When "semisuperevents" loss is omitted, the total loss cost function is reduced to

$$
f_{4}\left(x_{i j}\right)=\left[I_{0}+\left(1-I_{0}\right) \prod_{j=1}^{n_{i}} I_{j}\right] \sum_{j=1}^{n_{i}}\left(L_{0 j} x_{i j}\right) .
$$

To consider catastrophic, "superevents," which affect many/all suppliers, and "unique events" that affect only a single supplier, we develop the following four-objective programming models by adding objective of minimizing $f_{4}\left(x_{i j}\right)$ into the first programming model.

$$
\begin{aligned}
& \max \quad f_{1}\left(x_{i j}\right)=\sum_{i=1}^{m} D_{i} s_{i}-\sum_{i=1}^{m} \sum_{j=1}^{n_{i}} c_{i j} x_{i j} \\
& \min f_{2}\left(x_{i j}\right)=l \sum_{i=1}^{m} \sum_{j=1}^{n_{i}} \tau_{i j} x_{i j} \\
& \min \quad f_{3}\left(x_{i j}\right)=k \sum_{i=1}^{m} \sum_{j=1}^{n_{i}} \lambda_{i j} x_{i j} \\
& \min \quad f_{4}\left(x_{i j}\right) \\
& =\left[I_{0}+\left(1-I_{0}\right) \prod_{j=1}^{n_{i}} I_{j}\right] \sum_{j=1}^{n_{i}}\left(L_{0 j} x_{i j}\right)
\end{aligned}
$$

subject to: $\quad \sum_{j=1}^{n_{i}} x_{i j} \geq D_{i}, \quad i=1, \ldots, m$

$$
\begin{array}{ll}
x_{i j} \leq u_{i j}, & \forall i, j \\
x_{i j} \leq w_{i j}, \quad \forall i, j \\
x_{i j} \geq 0,
\end{array}
$$

where $j=1,2, \ldots, n_{i}$ represents the possible vendors selected for the $i$ th customer. The above model simultaneously maximizes the total profits $\left(f_{1}\left(x_{i j}\right)\right)$ and minimizes the percentage of items delivered late $\left(f_{2}\left(x_{i j}\right)\right)$, percentage of items rejected $\left(f_{3}\left(x_{i j}\right)\right)$, and the total loss cost $\left(f_{4}\left(x_{i j}\right)\right)$ due to supplier dysfunction, while satisfying various constraints with respect to minimum and maximum order quantities.

Customers' demand, which is formulated by a random fuzzy variable, is usually estimated by large amount of historical data and expert's assessment simultaneously. Customers' purchase cost, percentage of items being late, and percentage of rejected items are assumed to be fuzzy variables to handle the recognitive uncertainty due to lack of knowledge and historical data of different set of suppliers. Hence, we suggest a mixed MOP model by allowing $\widetilde{\widetilde{D}}_{i}$ to be random fuzzy variable and some parameters in the above model to be fuzzy data [25-28].

$$
\begin{array}{ll}
\max & f_{1}\left(x_{i j}\right)=\sum_{i=1}^{m} \tilde{\bar{D}}_{i} s_{i}-\sum_{i=1}^{m} \sum_{j=1}^{n_{i}} \widetilde{c}_{i j} x_{i j} \\
\min & f_{2}\left(x_{i j}\right)=l \sum_{i=1}^{m} \sum_{j=1}^{n_{i}} \widetilde{\tau}_{i j} x_{i j} \\
\min \quad f_{3}\left(x_{i j}\right)=k \sum_{i=1}^{m} \sum_{j=1}^{n_{i}} \widetilde{\lambda}_{i j} x_{i j} \\
\min \quad f_{4}\left(x_{i j}\right) \\
=\left[I_{0}+\left(1-I_{0}\right) \prod_{j=1}^{n_{i}} I_{j}\right] \sum_{j=1}^{n_{i}}\left(L_{0 j} x_{i j}\right)
\end{array}
$$

subject to: $\quad \sum_{j=1}^{n_{i}} x_{i j} \geq \stackrel{\tilde{D}}{D}_{i}, \quad i=1, \ldots, m$

$$
\begin{aligned}
& x_{i j} \leq u_{i j}, \quad \forall i, j \\
& x_{i j} \leq w_{i j}, \quad \forall i, j \\
& x_{i j} \geq 0,
\end{aligned}
$$

where " $\simeq$ " denotes a random fuzzy variable and “ $\sim$ " denotes fuzzy variable.

Theorem 1. Assume that the random variable $\bar{D}_{i}(\theta)$ is characterized by the following density function:

$$
P_{\overline{D_{i}}}(x)=\frac{1}{\sqrt{2 \pi} \sigma_{i}} e^{-\left(x-\widetilde{\mu}_{i}(\theta)\right)^{2} / 2 \sigma_{i}^{2}},
$$

where the fuzzy variable $\widetilde{u}_{i}(\theta), \theta \in \Theta$, has the following membership function:

$$
\mu_{\widetilde{u}_{i}^{D}(\theta)}(t)= \begin{cases}L\left(\frac{b_{i}^{D}-t}{a_{i}^{D}}\right), & t \leq b_{i}^{D}, a_{i}^{D}>0 \\ R\left(\frac{t-b_{i}^{D}}{c_{i}^{D}}\right), & t \geq b_{i}^{D}, c_{i}^{D}>0,\end{cases}
$$


where $a_{i}^{D}, c_{i}^{D}$ are positive numbers expressing the left and right spreads of $b_{i}{ }^{D}$ which is the average value of $\widetilde{u}_{i}$. Functions $L, R$ : $[0,1] \rightarrow[0,1]$ with $L(1)=R(1)=0$ and $L(0)=R(0)=1$ are nonincreasing continuous functions. Then we have

$$
\begin{aligned}
E\left(\tilde{\tilde{D}}_{i}\right)= & b_{i}^{D}+\frac{a_{i}^{D}}{2}\left[F_{L}\left(b_{i}^{D}\right)-F_{L}\left(a_{i}^{D}\right)\right] \\
& +\frac{c_{i}^{D}}{2}\left[F_{R}\left(b_{i}^{D}\right)-F_{R}\left(c_{i}^{D}\right)\right],
\end{aligned}
$$

where $F_{L}(x)$ and $F_{R}(x)$ are continuous functions while $F_{L}^{\prime}(x)=$ $L(x), x \in\left[a_{i}^{D}, b_{i}^{D}\right]$, and $F_{R}^{\prime}(x)=L(x), x \in\left[b_{i}^{D}, c_{i}^{D}\right]$.

Proof. The proof can be found in Appendix A.

Theorem 2. Assume that the fuzzy parameter $\tilde{c}_{i j}$ is a triangular fuzzy variable, denoted by $\left(a_{i j}^{c}, b_{i j}^{c}, c_{i j}^{c}\right), a_{i j}^{c}>0$. Then we have

$$
\begin{aligned}
& E\left[f_{4}\left(x_{i j}\right)\right] \\
& \quad=\left[p \prod_{j=1}^{n_{i}}\left(1-\pi_{j}\right)+(1-p) \prod_{j=1}^{n_{i}} \pi_{j}\right] \sum_{j=1}^{n_{i}}\left(L_{0 j} x_{i j}\right)
\end{aligned}
$$

and for $0 \leq \alpha_{i}, \beta_{i} \leq 1$,

$$
\begin{aligned}
& \operatorname{Ch}\left\{\widetilde{\bar{D}}_{i} \leq \sum_{j=1}^{n_{i}} x_{i j}\right\}\left(\alpha_{i}\right) \geq \beta_{i} \Longleftrightarrow \\
& b_{i}{ }^{D} \geq \sum_{j=1}^{n_{i}} x_{i j}-\sigma \Phi^{-1}\left(\beta_{i}\right) \\
& \quad \geq \max \left\{a_{i}^{D}, b_{i}^{D}-a_{i}{ }^{D} L^{-1}\left(\alpha_{i}\right)\right\} .
\end{aligned}
$$

Proof. The proof can be found in Appendix A.

Finally, the proposed novel multiobjective programming model for supply chain risk management under mixed uncertainty can be converted into the following deterministic one:

$$
\begin{array}{ll}
\max & f_{1}\left(x_{i j}\right)=E\left(\sum_{i=1}^{m} \stackrel{\tilde{D}_{i}}{s_{i}}-\sum_{i=1}^{m} \sum_{j=1}^{n_{i}} \widetilde{c}_{i j} x_{i j}\right) \\
\min & f_{2}\left(x_{i j}\right)=E\left(l \sum_{i=1}^{m} \sum_{j=1}^{n_{i}} \tilde{\tau}_{i j} x_{i j}\right) \\
\min \quad f_{3}\left(x_{i j}\right)=E\left(k \sum_{i=1}^{m} \sum_{j=1}^{n_{i}} \widetilde{\lambda}_{i j} x_{i j}\right) \\
\min \quad f_{4}\left(x_{i j}\right) \\
=\left[p \prod_{j=1}^{n_{i}}\left(1-\pi_{j}\right)+(1-p) \prod_{j=1}^{n_{i}} \pi_{j}\right] \sum_{j=1}^{n_{i}}\left(L_{0 j} x_{i j}\right)
\end{array}
$$

$$
\begin{array}{ll}
\text { subject to: } & b_{i}{ }^{D} \geq \sum_{j=1}^{n_{i}} x_{i j}-\sigma \Phi^{-1}\left(\beta_{i}\right) \\
& \geq \max \left\{a_{i}{ }^{D}, b_{i}{ }^{D}-a_{i}{ }^{D} L^{-1}\left(\alpha_{i}\right)\right\} \\
& \sum_{j=1}^{n_{i}} x_{i j}-\sigma \Phi^{-1}\left(\beta_{i}\right) \geq b_{i}{ }^{D}, \\
& i=1, \ldots, m, \alpha_{i} \geq 0, \beta_{i} \geq 0 \\
& x_{i j} \leq \min \left\{u_{i j}, w_{i j}\right\} \quad \forall i, j \\
& x_{i j} \geq 0,
\end{array}
$$

where $E\left(\stackrel{\tilde{D}}{i}_{i}\right)=b_{i}{ }^{D}+\left(a_{i}^{D} / 2\right)\left[F_{L}\left(b_{i}^{D}\right)-F_{L}\left(a_{i}^{D}\right)\right]+$ $\left(c_{i}^{D} / 2\right)\left[F_{R}\left(b_{i}^{D}\right)-F_{R}\left(c_{i}^{D}\right)\right], E\left(\widetilde{c}_{i j}\right)=\left(a_{i j}^{c}+2 b_{i j}^{c}+c_{i j}^{c}\right) / 4, E\left(\tilde{\beta}_{i j}\right)=$ $\left(a_{i j}^{\beta}+2 b_{i j}^{\beta}+c_{i j}^{\beta}\right) / 4$, and $E\left(\widetilde{\lambda}_{i j}\right)=\left(a_{i j}^{\lambda}+2 b_{i j}^{\lambda}+c_{i j}^{\lambda}\right) / 4$.

\section{Comprised Solution-Based Genetic Algorithm}

Genetic algorithms (GAs) have received considerable attention regarding their potential for providing a novel approach to multiobjective optimization problems, resulting in a fresh body of research and applications known as genetic multiobjective optimizations. For many real world problems, the set of Pareto solutions may be very large, so it is hard to solve them. In addition, to evaluate a large set of Pareto solutions and to select the best one pose a considerable cognitive burden on the decision maker. Therefore, in this case, obtaining the entire set of Pareto solutions is of little interest to decision makers. For overcoming such difficulties, Gen and Cheng [29] proposed a compromise approach which aims to search for compromise solutions instead of generating all Pareto solutions.

The compromise approach can be regarded as a kind of mathematical formulation of goal-seeking behavior in terms of a distance function. In this case, the compromise approach is given as follows: Suppose the ideal point of the decision maker is $f_{k}^{*}\left(x_{i j}\right)$. For each feasible solution $x_{i j}$, the regret function $r\left(x_{i j}, 2\right)$ is defined as follows:

$$
r\left(x_{i j}, 2\right)=\left[\sum_{k=1}^{4} w_{k}^{2}\left(f_{k}\left(x_{i j}\right)-f_{k}^{*}\left(x_{i j}\right)\right)^{2}\right]^{1 / 2},
$$

where weights $w=\left(w_{1}, w_{2}, w_{3}, w_{4}\right)$ are assigned to signal different degrees of importance. Hereby, we use a proxy ideal point introduced by Ghodsypour and O'Brien [21] to replace the ideal point $f_{k}^{*}\left(x_{i j}\right)$. Above all, we illustrate the compromise solution-based genetic algorithm procedure as follows and the pseudocodes can be found in Appendix B.

Step 0. Input the parameters including the number of chromosomes $\left(N_{\text {pop-size }}\right)$, crossover probability $\left(P_{\lambda}\right)$, and mutation probability $\left(P_{m}\right)$.

Step 1. Initialize $N_{\text {pop-size }}$ chromosomes by randomly searching in the feasible region. 
TABLE 1: Some parameters $\left(\widetilde{c}_{i j}, \widetilde{\tau}_{i j}, \widetilde{\lambda}_{i j}\right)$ for suppliers and customers.

\begin{tabular}{|c|c|c|c|c|c|}
\hline & 1 & 2 & 3 & 4 & 5 \\
\hline & $(0.8,0.9,1)$ & $(0.7,0.75,0.8)$ & $(0.93,0.97,1.01)$ & $(0.8,0.86,0.92)$ & $(0.55,0.58,0.61)$ \\
\hline \multirow[t]{3}{*}{1} & $(0.008,0.01,0.012)$ & $(0.018,0.02,0.022)$ & $(0.013,0.014,0.015)$ & $(0.025,0.027,0.029)$ & $(0.016,0.017,0.018)$ \\
\hline & $(0.01,0.02,0.03)$ & $(0.027,0.03,0.033)$ & $(0.023,0.025,0.027)$ & $(0.018,0.02,0.022)$ & $(0.04,0.041,0.042)$ \\
\hline & $(0.86,0.85,0.87)$ & $(0.59,0.6,0.61)$ & $(0.84,0.85,0.86)$ & $(0.98,0.99,0.1)$ & $(0.97,0.98,0.99)$ \\
\hline \multirow[t]{3}{*}{2} & $(0.01,0.011,0.012)$ & $(0.02,0.021,0.022)$ & $(0.03,0.037,0.041)$ & $(0.005,0.0051,0.0052)$ & $(0.06,0.061,0.062)$ \\
\hline & $(0.01,0.02,0.03)$ & $(0.031,0.033,0.035)$ & $(0.031,0.032,0.033)$ & $(0.021,0.022,0.023)$ & $(0.03,0.04,0.05)$ \\
\hline & $(1,1.01,1.02)$ & $(0.84,0.87,0.9)$ & $(0.9,0.91,0.92)$ & $(0.99,1,1.01)$ & $(1.01,1.02,1.03)$ \\
\hline \multirow[t]{3}{*}{3} & $(0.027,0.028,0.029)$ & $(0.014,0.015,0.016)$ & $(0.018,0.02,0.022)$ & $(0.008,0.01,0.012)$ & $(0.025,0.027,0.029)$ \\
\hline & $(0.018,0.02,0.022)$ & $(0.032,0.035,0.038)$ & $(0.027,0.03,0.033)$ & $(0.01,0.02,0.03)$ & $(0.033,0.04,0.047)$ \\
\hline & $(0.91,0.93,0.95)$ & $(0.9,0.92,0.94)$ & $(0.98,1,1.02)$ & $(1,1.02,1.04)$ & $(0.96,0.98,1)$ \\
\hline \multirow[t]{3}{*}{4} & $(0.021,0027,0.033)$ & $(0.02,0.03,0.04)$ & $(0.005,0.0051,0.0052)$ & $(0.03,0.037,0.041)$ & $(0.0134,0.0135,0.0136)$ \\
\hline & $(0.02,0.024,0.028)$ & $(0.022,0.024,0.026)$ & $(0.025,0.029,0.034)$ & $(0.01,0.02,0.03)$ & $(0.034,0.036,0.038)$ \\
\hline & $(0.98,1,1.02)$ & $(0.96,0.98,1)$ & $(1.01,1.03,1.05)$ & $(1,1.02,1.04)$ & $(1.02,1.03,1.04)$ \\
\hline \multirow[t]{3}{*}{5} & $(0.008,0.01,0.012)$ & $(0.02,0.021,0.022)$ & $(0.008,0.01,0.012)$ & $(0.01,0.011,0.012)$ & $(0.027,0.028,0.029)$ \\
\hline & $(0.015,0.018,0.021)$ & $(0.032,0.035,0.038)$ & $(0.032,0.035,0.038)$ & $(0.017,0.02,0.023)$ & $(0.0366,0.037,0.0376)$ \\
\hline & $(0.97,1,1.03)$ & $(0.96,0.97,0.98)$ & $(0.74,0.76,0.78)$ & $(1,1.01,1.02)$ & $(0.99,1.01,1.03)$ \\
\hline \multirow[t]{3}{*}{6} & $(0.024,0.026,0.028)$ & $(0.018,0.02,0.022)$ & $(0.006,0.0061,0.0062)$ & $(0.013,0.014,0.015)$ & $(0.023,0.0233,0.0236)$ \\
\hline & $(0.015,0.02,0.025)$ & $(0.027,0.03,0.033)$ & $(0.02,0.03,0.04)$ & $(0.023,0.025,0.027)$ & $(0.03,0.039,0.048)$ \\
\hline & $(0.85,0.87,0.89)$ & $(0.81,0.82,0.83)$ & $(0.9,0.92,0.94)$ & $(0.86,0.87,0.88)$ & $(0.86,0.88,0.9)$ \\
\hline \multirow[t]{3}{*}{7} & $(0.024,0.0245,0.025)$ & $(0.026,0.026,0.026)$ & $(0.03,0.037,0.041)$ & $(0.008,0.01,0.012)$ & $(0.022,0.023,0.024)$ \\
\hline & $(0.02,0.02,0.02)$ & $(0.02,0.03,0.04)$ & $(0.031,0.032,0.033)$ & $(0.01,0.02,0.03)$ & $(0.03,0.04,0.05)$ \\
\hline & $(0.99,1,1.01)$ & $(0.98,1,1.02)$ & $(1.18,1.2,1.22)$ & $(0.86,0.88,0.9)$ & $(0.95,0.98,1.01)$ \\
\hline \multirow[t]{3}{*}{8} & $(0.01,0.0112,0.0124)$ & $(0.013,0.014,0.015)$ & $(0.05,0.051,0.052)$ & $(0.025,0.027,0.029)$ & $(0.0122,0.0123,0.0124)$ \\
\hline & $(0.01,0.02,0.03)$ & $(0.023,0.025,0.027)$ & $(0.021,0.03,0.039)$ & $(0.0015,0.019,0.024)$ & $(0.03,0.04,0.05)$ \\
\hline & $(0.99,1,1.01)$ & $(0.96,0.98,1)$ & $(1.01,1.03,1.05)$ & $(0.58,0.6,0.62)$ & $(0.73,0.75,0.77)$ \\
\hline \multirow[t]{3}{*}{9} & $(0.018,0.02,0.022)$ & $(0.027,0.028,0.029)$ & $(0.02,0.022,0.024)$ & $(0.02,0.021,0.022)$ & $(0.02,0.03,0.04)$ \\
\hline & $(0.025,0.03,0.035)$ & $(0.022,0.024,0.026)$ & $(0.03,0.033,0.036)$ & $(0.029,0.03,0.031)$ & $(0.035,0.039,0.044)$ \\
\hline & $(0.99,1,1.01)$ & $(1,1.01,1.02)$ & $(1.02,1.03,1.04)$ & $(0.96,0.97,0.98)$ & $(0.98,1.01,1.04)$ \\
\hline \multirow[t]{2}{*}{10} & $(0.001,0.002,003)$ & $(0.008,0.01,0.012)$ & $(0.013,0.014,0.015)$ & $(0.023,0.024,0.025)$ & $(0.052,0.053,0.054)$ \\
\hline & $(0.028,0.03,0.032)$ & $(0.01,0.02,0.03)$ & $(0.031,0.032,0.033)$ & $(0.023,0.025,0.027)$ & $(0.035,0.04,0.045)$ \\
\hline
\end{tabular}

Step 2. Update the chromosomes by crossover and mutation operations after checking the feasibility of offspring.

Step 3. Compute the fitness of each chromosome on the basis of the regret value.

Step 4. Select the chromosomes by spinning the roulette wheel.

Step 5. Repeat the second to fourth steps for a given number of cycles.

Step 6. Output the best chromosome as the optimal solution.

\section{Numerical Example}

A supply chain with five suppliers and ten customers is listed in Table 1, which covers the unit purchase cost from supplier $j$ by the $i$ th customer, percentage of items late from supplier $j$ to the $i$ th customer, and percentage of rejected units from supplier $j$. The demand ${\stackrel{\widetilde{D}}{D_{i}}}_{i}$ assumed
TABle 2: Demand data of customers.

\begin{tabular}{lccc}
\hline Customer & $\mu_{i}$ & $\sigma_{i}$ & $s_{i}$ \\
\hline$D 1$ & $(28,30,32)$ & 1.0 & 10 \\
$D 2$ & $(26,28,30)$ & 1.0 & 9.5 \\
$D 3$ & $(21,22,23)$ & 1.2 & 10.5 \\
$D 4$ & $(17,18,19)$ & 0.8 & 8 \\
$D 5$ & $(14.5,15,15.5)$ & 0.7 & 7.5 \\
$D 6$ & $(12,13,14)$ & 1.0 & 10 \\
$D 7$ & $(11,12,13)$ & 0.9 & 9 \\
$D 8$ & $(11,12,13)$ & 0.6 & 7.5 \\
$D 9$ & $(11.5,12,12.5)$ & 0.7 & 9 \\
$D 10$ & $(11.5,11,11.5)$ & 0.9 & 10 \\
\hline
\end{tabular}

to be distributed as $N\left(\widetilde{u}_{i}, \sigma_{i}^{2}\right)$ for a given period is listed in Table 2. The retailer must anticipate demand and order quantities of the modeled good to be delivered to arrive on time at each demand destination. Profit could be obtained from sales with successfully goods delivery to each demand. 
TABLE 3: Solutions with different confidence levels.

\begin{tabular}{cccccc}
\hline & $x_{11}$ & $x_{31}$ & $x_{41}$ & $x_{71}$ & $x_{81}$ \\
$\alpha_{i}=0.9$ & 31.08 & 23.436 & 18.924 & 13.052 & 12.668 \\
$\beta_{i}=0.9$ & $x_{101}$ & $x_{22}$ & $x_{62}$ & $x_{53}$ & $x_{94}$ \\
& 12.602 & 29.08 & 14.18 & 15.846 & 12.796 \\
\hline & $x_{11}$ & $x_{31}$ & $x_{41}$ & $x_{71}$ & $x_{81}$ \\
$\alpha_{i}=0.75$ & 30.87 & 23.18 & 18.75 & 12.86 & 12.54 \\
$\beta_{i}=0.75$ & $x_{101}$ & $x_{22}$ & $x_{62}$ & $x_{53}$ & $x_{94}$ \\
& 12.41 & 28.87 & 13.97 & 15.69 & 12.65 \\
\hline & $x_{11}$ & $x_{31}$ & $x_{41}$ & $x_{71}$ & $x_{81}$ \\
$\alpha_{i}=0.6$ & 30.44 & 22.66 & 18.40 & 12.48 & 12.28 \\
$\beta_{i}=0.6$ & $x_{101}$ & $x_{22}$ & $x_{62}$ & $x_{53}$ & $x_{94}$ \\
& 12.03 & 28.44 & 13.54 & 15.40 & 12.35 \\
\hline
\end{tabular}

The corresponding selling price $s_{i}$ is listed in Table 3. Costs are probabilistic as outlined above, but total cost of goods sales has a mean given for each source supplier. Goods not passing quality acceptance level are not paid for. Goods delivered late are paid for at a reduced rate and are carried forward at an inventory cost. We then set $u_{i j}=w_{i j}=50$. Furthermore, following Choi et al. [1], we assume deterministic loss and operating cost. Therefore, we also have $L_{0 j}=50(j=$ $1,2, \ldots, 5), P=0.02$, and $\pi_{1}=\pi_{2}=\pi_{3}=\pi_{4}=\pi_{5}=0.05$. It is a natural state that both the probability of one of the superevents and the probability of the unique event occurring during the supply cycle for supplier are normal.

Table 1 lists the value of each triangular fuzzy parameter. For example, the set of data in the 1st row 1st column denotes the unit purchased cost $\widetilde{c}_{11}(0.8,0.9,1)$, the percentage of rejected items $\widetilde{\tau}_{11}(0.008,0.01,0.012)$, and the percentage of items late $\tilde{\lambda}_{11}(0.01,0.02,0.03)$ from the 1st supplier to the 1st customer, respectively. These data could be set by analyzing the distributing of correlative historical data collected by each supplier. Take $\widetilde{c}_{11}$, for example. The 1st supplier analyzes the data of unit purchased cost within past 10 periods and finds the data is distributed in $[0.8,1]$. We depict it with triangular fuzzy parameter. Ten demand sites have been modeled in the same way. Different conditions could be modeled with little difficulty other than scale.

The $x_{i j}$ in Table 3 means that the chosen supplier $j$ by the customer $i$ and the set of solution achieve the optimal value of objective functions. Table 3 shows that, in the condition that makes other parameters changeless, the value of solutions can be affected by the different $\alpha_{i}$ and $\beta_{i}$ while the distributing of solutions unaltered. In the following sections, we concentrate on the influence from the parameters $\stackrel{\widetilde{D}}{\tilde{D}_{i}}, \widetilde{c}_{i j}, \widetilde{\tau}_{i j}$, and $\tilde{\lambda}_{i j}$ to the solutions. We fix up the parameter of confidence level $\left(\alpha_{i}=\right.$ $\left.0.9 ; \beta_{i}=0.9\right)$.

As we know, the parameter $\widetilde{\bar{D}}_{i}$ denotes the demand for item over planning period from the $i$ th customer. $\stackrel{\sim}{D}_{i}$ is a random fuzzy variable with the mean $\mu_{i}$ and the variance $\sigma_{i}$. Different sets of $\mu_{i}$ and $\sigma_{i}$ are given in Table 4 and the corresponding sets of $x_{i j}$ are listed in Figure 1.

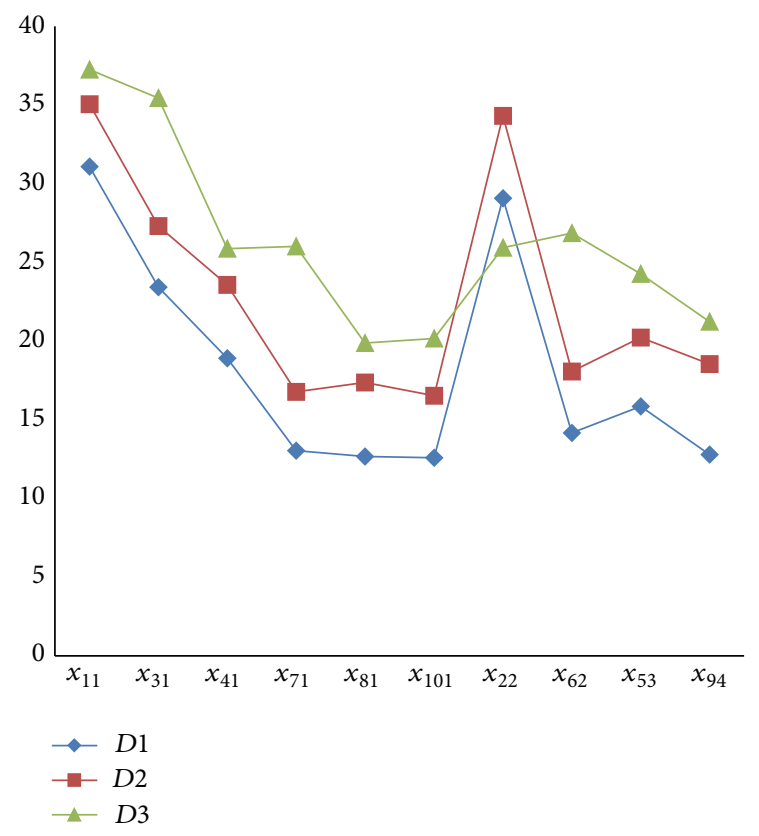

FIGURE 1: Solutions with different customer demands.

Parameter $\tilde{c}_{i j}$ denotes the purchasing cost from the supplier to customers. The value of the cost always changed with the market. We assume different groups of $\widetilde{c}_{i j}$ and the results in Table 5 .

In Table 5, C1 denotes the situation of the mean of costs of all suppliers having increased 0.1, C2 denotes the situation of the mean of the purchasing costs of the 1st supplier having increased 0.1, and C3 denotes the situation of the mean of the purchasing costs of the 1st and 2nd supplier having increased. The results show that the distribution of solutions alters along with the alteration of $\widetilde{c}_{i j}$. Videlicet, the cost is one of the factors which lead customers to select the supplier.

We then set three groups of $\widetilde{\tau}_{i j}$, the parameter of percentage of rejected items from supplier. Table 6 and Figure 2 show the results. $T 1$ denote the original situation. $T 2$ denote the situation of the percentage of rejected items of the 4 th and 5 th suppliers having been reduced and T3 for that of the 1st and 2 nd having been increased.

The results show that the distribution of solutions varies along with the alteration of $\tilde{\tau}_{i j}$, and the parameter of items delayed by suppliers $\lambda_{i j}$ also impacts the distribution of solutions.

The foregoing computation and analysis are based on a common state that both the probability of one of the superevents and the probability of the unique event occurring during the supply cycle for supplier are normal. In Table 7, we assume three kinds of risk situations, denoted as $R 1$ (the common state), $R 2$ (the probability of superevents increased and all the unit financial loss $L_{0 j}(j=1,2, \ldots, 5)$ increased accordingly), and $R 3$ (the probability of unique event occurring for the 1st and 2nd supplier increased and the unit financial loss $L_{01}$ and $L_{02}$ altered simultaneity). Figure 3 shows the solutions.

The results show that superevents have no influence on the distribution of solutions. The customers take the same 
TABLE 4: Different customer demands.

\begin{tabular}{|c|c|c|c|c|c|c|c|c|}
\hline$\tilde{\bar{D}}_{i 1}$ & $\mu_{i}$ & $\sigma_{i}$ & $\bar{D}_{i 2}$ & $\mu_{i}$ & $\sigma_{i}$ & $\bar{D}_{i 3}$ & $\mu_{i}$ & $\sigma_{i}$ \\
\hline$D 1$ & $(30,34,38)$ & 1.0 & $D 1$ & $(28,30,32)$ & 1.2 & $D 1$ & $(34,36,32)$ & 1.2 \\
\hline D2 & $(28,32,36)$ & 1.0 & D2 & $(26,28,30)$ & 1.2 & D2 & $(32,34,36)$ & 1.2 \\
\hline D3 & $(23,26,29)$ & 1.2 & D3 & $(21,22,23)$ & 1.4 & D3 & $(33,34,35)$ & 1.4 \\
\hline D4 & $(19,22,25)$ & 0.8 & $D 4$ & $(17,18,19)$ & 1.0 & $D 4$ & $(23,24,25)$ & 1.0 \\
\hline D5 & $(16.5,19,21.5)$ & 0.7 & D5 & $(14.5,15,15.5)$ & 0.9 & D5 & $(20.5,21,21.5)$ & 0.9 \\
\hline D6 & $(14,17,20)$ & 1.0 & D6 & $(12,13,14)$ & 1.2 & D6 & $(24,25,26)$ & 1.2 \\
\hline D7 & $(13,16,19)$ & 0.9 & D7 & $(11,12,13)$ & 1.1 & D7 & $(23,24,25)$ & 1.1 \\
\hline D8 & $(13,16,21)$ & 0.6 & $D 8$ & $(11,12,13)$ & 0.8 & $D 8$ & $(17,18,19)$ & 0.8 \\
\hline D9 & $(13.5,16,18.5)$ & 0.7 & D9 & $(11.5,12,12.5)$ & 0.9 & D9 & $(17.5,18,18.5)$ & 0.9 \\
\hline$D 10$ & $(13.5,15,19.5)$ & 0.9 & $D 10$ & $(11.5,11,11.5)$ & 1.1 & $D 10$ & $(17.5,18,19.5)$ & 1.1 \\
\hline
\end{tabular}

TABLE 5: Solutions with different costs.

\begin{tabular}{cccccc}
\hline & $x_{11}$ & $x_{31}$ & $x_{41}$ & $x_{71}$ & $x_{81}$ \\
$C 1$ & 31.08 & 23.436 & 18.924 & 13.052 & 12.668 \\
& $x_{101}$ & $x_{22}$ & $x_{62}$ & $x_{53}$ & $x_{94}$ \\
& 12.602 & 29.08 & 14.18 & 15.846 & 12.796 \\
\hline & $x_{41}$ & $x_{71}$ & $x_{101}$ & $x_{12}$ & $x_{22}$ \\
& 18.924 & 13.052 & 12.602 & 31.08 & 29.08 \\
$C 2$ & $x_{32}$ & $x_{62}$ & $x_{53}$ & $x_{84}$ & $x_{94}$ \\
& 23.436 & 14.18 & 15.846 & 12.668 & 12.796 \\
\hline & $x_{41}$ & $x_{22}$ & $x_{62}$ & $x_{53}$ & $x_{14}$ \\
& 18.924 & 29.08 & 14.18 & 15.846 & 31.08 \\
$C 3$ & $x_{34}$ & $x_{74}$ & $x_{84}$ & $x_{94}$ & $x_{104}$ \\
& 23.436 & 13.052 & 12.668 & 12.796 & 12.602 \\
\hline
\end{tabular}

TABLE 6: Solutions with different percentage of rejected items.

\begin{tabular}{cccccc}
\hline & $x_{11}$ & $x_{31}$ & $x_{41}$ & $x_{71}$ & $x_{81}$ \\
$T 1$ & 31.08 & 23.436 & 18.924 & 13.052 & 12.668 \\
& $x_{101}$ & $x_{22}$ & $x_{62}$ & $x_{53}$ & $x_{94}$ \\
& 12.602 & 29.08 & 14.18 & 15.846 & 12.796 \\
\hline & $x_{41}$ & $x_{71}$ & $x_{22}$ & $x_{62}$ & $x_{53}$ \\
& 18.924 & 13.052 & 29.08 & 14.18 & 15.846 \\
$T 2$ & $x_{34}$ & $x_{84}$ & $x_{94}$ & $x_{104}$ & $x_{15}$ \\
& 23.436 & 12.668 & 12.796 & 12.602 & 31.08 \\
\hline & $x_{23}$ & $x_{53}$ & $x_{63}$ & $x_{14}$ & $x_{34}$ \\
& 29.08 & 15.846 & 14.18 & 31.08 & 23.436 \\
$T 3$ & $x_{44}$ & $x_{74}$ & $x_{84}$ & $x_{94}$ & $x_{104}$ \\
& 18.924 & 13.052 & 12.668 & 12.796 & 12.602 \\
\hline
\end{tabular}

decision making with the common state since the risk of each supplier is unchanged to customers. When unique event occurs for some suppliers, however, the distribution of solutions altered which means that the customer leans to the suppliers with lower probability of risk situations.

In the following parts, we will discuss the relation between the expected value of total profits and the total loss of risk in our model. Generally, people extend the demand for item and the selling price or reduce the costs in order to achieve

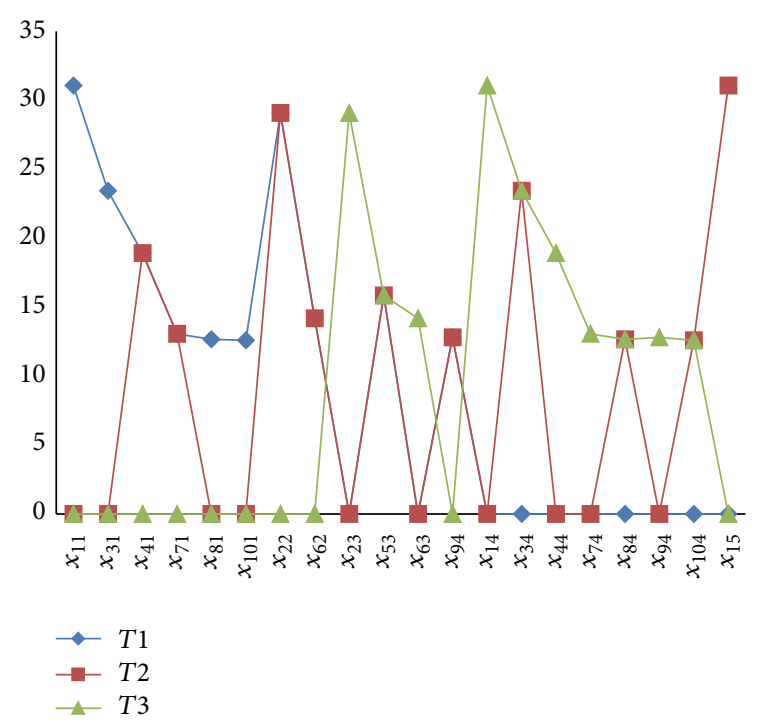

FIGURE 2: Solutions with different percentage of rejected items.

more profits. However, it is hard to control the variance of the selling price and costs of item, which are usually dominated by the fluctuation of market. It is reasonable and effective to adjust the parameters of demand. According to the MOP model and the analysis above, the value of solutions increases with the mean value of $\stackrel{\widetilde{D}}{D_{i}}$ added, and the value of total loss of risk increases simultaneously. We list several groups of parameter $\widetilde{\widetilde{D}}_{i}$, the corresponding relation between the expected value of total profits and the total loss of risk shown in Figure 4 which indicates the loss of risk while achieving more profits.

According to the analysis and computation above, this random fuzzy MOP with risk objective model reminds the decision maker that more profits bring more risk. In addition, the model indicates that quantity purchased $\left(x_{i j}\right)$ is impacted by both customer and supplier. The distribution of $x_{i j}$, which denotes the choosing of supplier from the customer, is affected by the costs $\left(c_{i j}\right)$, the quality $\left(\tau_{i j}\right)$, the service $\left(\lambda_{i j}\right)$, and the risk situations of different suppliers. The quantity $\left(x_{i j}\right)$ is determined mostly by the demand of customers $\stackrel{\sim}{D}_{i}$. 
TABLE 7: Solutions with different percentage of rejected items.

\begin{tabular}{|c|c|c|c|c|c|}
\hline$P=0.02$ & $x_{11}$ & $x_{31}$ & $x_{41}$ & $x_{71}$ & $x_{81}$ \\
\hline$\pi_{j}=0.05$ & 31.08 & 23.436 & 18.924 & 13.052 & 12.668 \\
\hline$L_{0 j}=50$ & $x_{101}$ & $x_{22}$ & $x_{62}$ & $x_{53}$ & $x_{94}$ \\
\hline$(j=1,2, \ldots, 5)$ & 12.602 & 29.08 & 14.18 & 15.846 & 12.796 \\
\hline$P=0.08$ & $x_{11}$ & $x_{31}$ & $x_{41}$ & $x_{71}$ & $x_{81}$ \\
\hline$\pi_{j}=0.05$ & 31.08 & 23.436 & 18.924 & 13.052 & 12.668 \\
\hline$L_{0 j}=60$ & $x_{101}$ & $x_{22}$ & $x_{62}$ & $x_{53}$ & $x_{94}$ \\
\hline$(j=1,2, \ldots, 5)$ & 12.602 & 29.08 & 14.18 & 15.846 & 12.796 \\
\hline$P=0.02, \pi_{1}=0.1$ & $x_{23}$ & $x_{53}$ & $x_{63}$ & $x_{14}$ & $x_{34}$ \\
\hline$\pi_{j}=0.05, j=2, \ldots, 5$ & 29.08 & 15.846 & 14.18 & 31.08 & 23.436 \\
\hline$L_{01}=60$ & $x_{44}$ & $x_{74}$ & $x_{84}$ & $x_{94}$ & $x_{104}$ \\
\hline$L_{0 j}=50, j=2, \ldots, 5$ & 18.924 & 13.052 & 12.668 & 12.796 & 12.602 \\
\hline
\end{tabular}

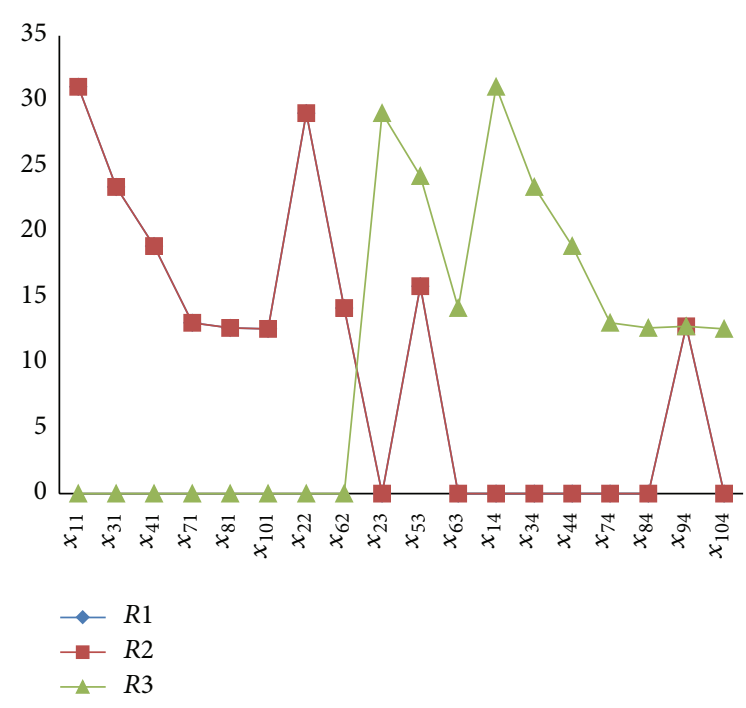

FIGURE 3: Solutions with different risk situations.

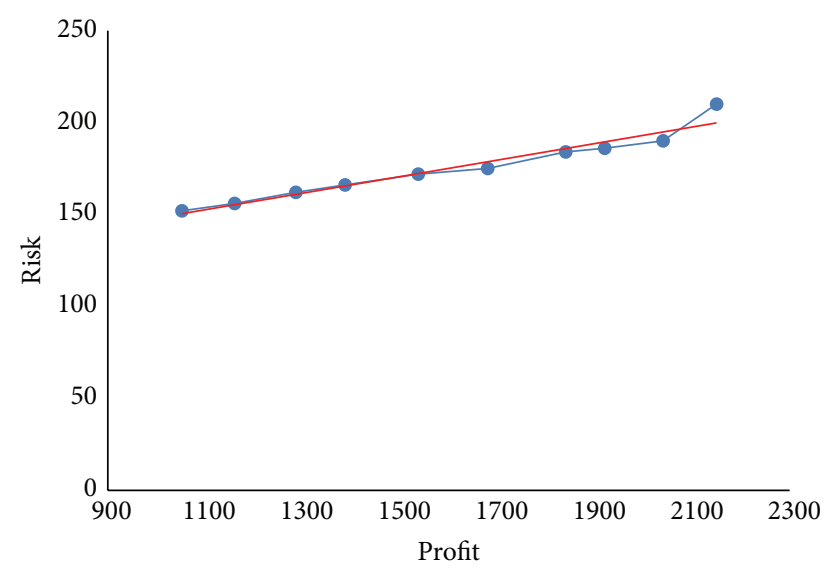

FIGURE 4: Relation between profits and risk.

\section{Managerial Implications}

Some implications about the contribution of our research to the supplier selection management and supply chain risk management are summarized as follows.
To consider catastrophic, "superevents," which affect many/all suppliers, and "unique events" that affect only a single supplier, effective forecast of the uncertainty and its possible impact on suppliers could help us make right supplier selection strategy. Furthermore, risk-averse ability could be taken as one of the important criteria for choosing the best suppliers.

In management practice, beyond traditional supplier selection system, by considering customer demand and unit purchase cost, we provide the decision maker with a simple tool for coordinating the flows of parts from suppliers to customers. The approach allows the managers to structure the distribution of cost or customer service level by selecting the optimal supply combination and scheduling of customer orders.

Application of the novel multiobjective programming with mixed uncertain coefficients could help the companies cope with the supply chain risk. The proposed model simultaneously maximizes the total profits and minimizes the percentage of items delivered late, percentage of items rejected, and the total loss cost due to supplier dysfunction.

\section{Conclusion}

Through analyzing three types of risk events in a supply chain system, (i) the superevents; (ii) when all suppliers close down during the supply cycle; and (iii) when some, but not all the suppliers, close down, we proposed a novel multiobjective programming with mixed uncertain coefficients developed for managing the supply chain risk. In this model, the customer demand is considered to be a random fuzzy variable and unit purchase cost is considered to be a fuzzy variable due to their uncertainty. According to the expected value and chance constraint operators, the uncertain model was converted into a deterministic one. By examining a numerical example, we found that (1) the confidence level and demand of customers have impact on the quantities purchased by customers from suppliers although the distribution of suppliers will not change; (2) the cost, the quality, and the service also influence the selection of suppliers; and (3) the superevents had little influence on the distribution of supplier selection; however, when unique event occurs, the distribution of supplier selection will change. 
Some other uncertainty and risk types are not considered in the present study. It is of great importance to further examine this issue in future research.

\section{Appendix}

\section{A. Proof of Theorems}

Proof of Theorem 1. Since $\bar{D}_{i}(\theta)$ is a random variable with the mean $\tilde{u}_{i}(\theta)$ and the variance $\sigma_{i}^{2}$, then $E\left[\tilde{\bar{D}}_{i}(\theta)\right]=\tilde{u}_{i}(\theta)$ is a fuzzy variable. By the membership function $\mu_{\widetilde{u}_{i}(\theta)}(t)$ of $\widetilde{u}_{i}(\theta)$ and the definition of credibility measure, we have

$$
\begin{aligned}
& \operatorname{Cr}\left\{\theta \mid E\left[\stackrel{\tilde{D}}{i}_{i}(\theta)\right] \geq t\right\} \\
& = \begin{cases}1, & t \leq a_{i}{ }^{D} \\
1-\frac{1}{2} L\left(\frac{b_{i}^{D}-t}{a_{i}^{D}}\right), & a_{i}{ }^{D} \leq t \leq b_{i}{ }^{D} \\
\frac{1}{2} R\left(\frac{t-b_{i}{ }^{D}}{c_{i}^{D}}\right), & b_{i}{ }^{D} \leq t \leq c_{i}{ }^{D} \\
0, & t \geq c_{i}{ }^{D} .\end{cases}
\end{aligned}
$$

It follows, from the definition of the expected value operator of random fuzzy variables, that

$$
\begin{aligned}
& E\left[\stackrel{\widetilde{D}}{i}_{i}\right]=\int_{0}^{+\infty} \operatorname{Cr}\left\{\theta \in \Theta \mid E\left[\widetilde{\tilde{D}}_{i}(\theta)\right] \geq t\right\} d t \\
& -\int_{-\infty}^{0} \operatorname{Cr}\left\{\theta \in \Theta \mid E\left[\stackrel{\tilde{D}}{D}_{i}(\theta)\right] \leq t\right\} d t \\
& =\int_{0}^{a_{i}^{D}} 1 d t+\int_{a_{i}{ }^{D}}^{b_{i}^{D}}\left[1-\frac{1}{2} L\left(\frac{b_{i}^{D}-t}{a_{i}{ }^{D}}\right)\right] d t \\
& +\int_{b_{i}{ }^{D}}^{c_{i}^{D}} \frac{1}{2} R\left(\frac{t-b_{i}^{D}}{c_{i}^{D}}\right) \\
& =b_{i}^{D}+\frac{a_{i}^{D}}{2}\left[F_{L}\left(b_{i}^{D}\right)-F_{L}\left(a_{i}^{D}\right)\right] \\
& +\frac{c_{i}^{D}}{2}\left[F_{R}\left(b_{i}^{D}\right)-F_{R}\left(c_{i}^{D}\right)\right]
\end{aligned}
$$

where $F_{L}(x)$ and $F_{R}(x)$ are continuous functions while $F_{L}^{\prime}(x)=L(x), x \in\left[a_{i}^{D}, b_{i}^{D}\right], F_{R}^{\prime}(x)=L(x)$, and $x \in\left[b_{i}^{D}, c_{i}^{D}\right]$. This completes the proof.

Proof of Theorem 2. According to Dickson [17] and Håkansson and Snehota [18], we have that

$$
\begin{aligned}
E\left(\widetilde{c}_{i j}\right) & =\int_{0}^{+\infty} \operatorname{Cr}\left\{\widetilde{c}_{i j} \geq r\right\} d r-\int_{-\infty}^{0} \operatorname{Cr}\left\{\widetilde{c}_{i j} \leq r\right\} d r \\
& =\frac{\left(a_{i j}^{c}+2 b_{i j}^{c}+c_{i j}^{c}\right)}{4} .
\end{aligned}
$$

Input: Initial data and GA parameters

Output: Optimal solutions and objective values Begin

$t \leftarrow 1$;

initialization $P\left(N_{\text {pop-size }}\right)$ by feasibility check;

fitness eval $(P)$;

while (not termination condition) do

selection();

crossover();

mutation();

evaluation $(t)$

$t \leftarrow t+1$

end

Output: Optimal solutions and objective values end

Pseudocode 1: Comprised solution-based GA.

For the risk objective $f_{4}\left(x_{i j}\right)$, in which $I_{0}$ and $I_{j}$ indicate random variable and lead the uncertainty, we use expected value operator of random variable in order to reduce the anticipative risk.

$$
\begin{aligned}
E & {\left[f_{4}\left(x_{i j}\right)\right] } \\
& =E\left\{\left[I_{0}+\left(1-I_{0}\right) \prod_{j=1}^{n_{i}} I_{j}\right] \sum_{j=1}^{n_{i}}\left(L_{0 j} x_{i j}\right)\right\} .
\end{aligned}
$$

From the preanalysis, we have

$$
\begin{aligned}
& P\left(I_{0}=1, I_{j}=0\right)=p \prod_{j=1}^{n_{i}}\left(1-\pi_{j}\right), \\
& P\left(I_{0}=0, I_{j}=1\right)=(1-p) \prod_{j=1}^{n_{i}} \pi_{j} .
\end{aligned}
$$

It follows that

$$
\begin{aligned}
E[ & \left.f_{4}\left(x_{i j}\right)\right] \\
= & p \prod_{j=1}^{n_{i}}\left(1-\pi_{j}\right) \sum_{j=1}^{n_{i}}\left(L_{0} x_{i j}\right) \\
& +(1-p) \prod_{j=1}^{n_{i}} \pi_{j} \sum_{j=1}^{n_{i}}\left(L_{0 j} x_{i j}\right) \\
= & {\left[p \prod_{j=1}^{n_{i}}\left(1-\pi_{j}\right)+(1-p) \prod_{j=1}^{n_{i}} \pi_{j}\right] \sum_{j=1}^{n_{i}}\left(L_{0 j} x_{i j}\right) . }
\end{aligned}
$$

According to the chance constraint, we have that, for $0 \leq \alpha_{i}$, $\beta \leq 1$, 


$$
\begin{aligned}
& \operatorname{Ch}\left\{\tilde{\bar{D}}_{i} \leq \sum_{j=1}^{n_{i}} x_{i j}\right\}\left(\alpha_{i}\right) \geq \beta_{i} \Longleftrightarrow \\
& \operatorname{Pos}\left\{\theta \mid \operatorname{Pr}\left\{\bar{D}_{i}(\theta) \leq \sum_{j=1}^{n_{i}} x_{i j}\right\} \geq \beta_{i}\right\} \geq \alpha_{i} \Longleftrightarrow \\
& \operatorname{Pos}\left\{\Phi\left(\frac{\sum_{j=1}^{n_{i}} x_{i j}-\tilde{\mu}_{i}^{D}(\theta)}{\sigma}\right) \geq \beta_{i}\right\} \geq \alpha_{i} \Longleftrightarrow \\
& \operatorname{Pos}\left\{\theta \mid \tilde{\mu}_{i}^{D}(\theta) \leq \sum_{j=1}^{n_{i}} x_{i j}-\sigma \Phi^{-1}(\beta)\right\} \geq \alpha_{i} \Longleftrightarrow \\
& \alpha_{i} \leq \begin{cases}0, & \text { if } \sum_{j=1}^{n_{i}} x_{i j}-\sigma \Phi^{-1}\left(\beta_{i}\right) \leq a_{i}^{D} \\
L\left(\frac{b_{i}^{D}-\left[\sum_{j=1}^{n_{i}} x_{i j}-\sigma \Phi^{-1}\left(\beta_{i}\right)\right]}{a_{i}^{D}}\right), & \text { if } a_{i}^{D} \leq \sum_{j=1}^{n_{i}} x_{i j}-\sigma \Phi^{-1}\left(\beta_{i}\right) \leq b_{i}^{D} \Longleftrightarrow \\
1, & \text { if } \sum_{j=1}^{n_{i}} x_{i j}-\sigma \Phi^{-1}\left(\beta_{i}\right) \geq b_{i}^{D}\end{cases} \\
& \sum_{j=1}^{n_{i}} x_{i j}-\sigma \Phi^{-1}\left(\beta_{i}\right) \geq \max \left\{a_{i}{ }^{D}, b_{i}^{D}-a_{i}{ }^{D} L^{-1}\left(\alpha_{i}\right)\right\},
\end{aligned}
$$

where $\operatorname{Ch}\{\cdot\}$ denotes the chance of the random fuzzy event and possibility $\alpha_{i}$ and probability $\beta_{i}$ are specified confidence levels. This completes the proof.

\section{B. Pseudo Codes}

See Pseudocode 1.

\section{Competing Interests}

The authors declare that they have no competing interests.

\section{Acknowledgments}

This research was supported by the National Natural Science Foundation for Young Scholars of China (Grant nos. 71301109 and 71403158), the Western and Frontier Region Project of Humanity and Social Sciences Research, Ministry of Education of China (Grant no. 13XJC630018), the Social Science Planning Project of Sichuan Province (Grant no. SC16A006), and China Postdoctoral Science Foundation Funded Project (Grant no. 2016M590960).

\section{References}

[1] T. M. Choi, C. H. Chiu, and H. K. Chan, "Risk management of logistics systems," Transportation Research Part E: Logistics and Transportation Review, vol. 90, pp. 1-6, 2016.
[2] P. D. Berger, A. Gerstenfeld, and A. Z. Zeng, "How many suppliers are best? A decision-analysis approach," Omega, vol. 32, no. 1, pp. 9-15, 2004.

[3] T. Sawik, "Joint supplier selection and scheduling of customer orders under disruption risks: single vs. dual sourcing," Omega, vol. 43, pp. 83-95, 2014.

[4] T. Sawik, "On the fair optimization of cost and customer service level in a supply chain under disruption risks," Omega, vol. 53, pp. 58-66, 2015.

[5] F. Hamdi, L. Dupont, A. Ghorbel, and F. Masmoudi, "Supplier selection and order allocation under disruption risk," IFACPapersOnLine, vol. 49, no. 12, pp. 449-454, 2016.

[6] S. A. Torabi, M. Baghersad, and S. A. Mansouri, "Resilient supplier selection and order allocation under operational and disruption risks," Transportation Research Part E: Logistics and Transportation Review, vol. 79, pp. 22-48, 2015.

[7] B. Fahimnia, C. S. Tang, H. Davarzani, and J. Sarkis, "Quantitative models for managing supply chain risks: a review," European Journal of Operational Research, vol. 247, no. 1, pp. 1-15, 2015.

[8] I. Heckmann, T. Comes, and S. Nickel, "A critical review on supply chain risk-definition, measure and modeling," Omega, vol. 52, pp. 119-132, 2015.

[9] F. Wiengarten, P. Humphreys, C. Gimenez, and R. McIvor, "Risk, risk management practices, and the success of supply chain integration," International Journal of Production Economics, vol. 171, pp. 361-370, 2016.

[10] A. F. Guneri, A. Yucel, and G. Ayyildiz, "An integrated fuzzylp approach for a supplier selection problem in supply chain management," Expert Systems with Applications, vol. 36, no. 5, pp. 9223-9228, 2009. 
[11] Z. Liao and J. Rittscher, "A multi-objective supplier selection model under stochastic demand conditions," International Journal of Production Economics, vol. 105, no. 1, pp. 150-159, 2007.

[12] G. Büyüközkan and G. Çifçi, "A novel fuzzy multi-criteria decision framework for sustainable supplier selection with incomplete information," Computers in Industry, vol. 62, no. 2, pp. 164-174, 2011.

[13] M. S. Memon, Y. H. Lee, and S. I. Mari, "Group multi-criteria supplier selection using combined grey systems theory and uncertainty theory," Expert Systems with Applications, vol. 42, no. 21, pp. 7951-7959, 2015.

[14] P. Amorim, E. Curcio, B. Almada-Lobo, A. P. F. D. BarbosaPóvoa, and I. E. Grossmann, "Supplier selection in the processed food industry under uncertainty," European Journal of Operational Research, vol. 252, no. 3, pp. 801-814, 2016.

[15] K. S. Moghaddam, "Fuzzy multi-objective model for supplier selection and order allocation in reverse logistics systems under supply and demand uncertainty," Expert Systems with Applications, vol. 42, no. 15-16, pp. 6237-6254, 2015.

[16] A. Azaron, K. N. Brown, S. A. Tarim, and M. Modarres, "A multi-objective stochastic programming approach for supply chain design considering risk," International Journal of Production Economics, vol. 116, no. 1, pp. 129-138, 2008.

[17] G. W. Dickson, "An analysis of vendor selection: system and decisions," Journal of Purchasing, vol. 1, pp. 5-17, 1966.

[18] H. Håkansson and I. Snehota, "No business is an island: the network concept of business strategy," Scandinavian Journal of Management, vol. 22, no. 3, pp. 256-270, 2006.

[19] D. L. Olson and D. Wu, "Simulation of fuzzy multiattribute models for grey relationships," European Journal of Operational Research, vol. 175, no. 1, pp. 111-120, 2006.

[20] A. A. Gaballa, "Minimum cost allocation of tenders," Journal of the Operational Research Society, vol. 25, no. 3, pp. 389-398, 1974.

[21] S. H. Ghodsypour and C. O'Brien, “The total cost of logistics in supplier selection, under conditions of multiple sourcing, multiple criteria and capacity constraint," International Journal of Production Economics, vol. 73, no. 1, pp. 15-27, 2001.

[22] S. Aghai, N. Mollaverdi, and M. S. Sabbagh, "A fuzzy multiobjective programming model for supplier selection with volume discount and risk criteria," The International Journal of Advanced Manufacturing Technology, vol. 71, no. 5-8, pp. 14831492, 2014.

[23] D. D. Wu, Y. Zhang, D. Wu, and D. L. Olson, "Fuzzy multiobjective programming for supplier selection and risk modeling: a possibility approach," European Journal of Operational Research, vol. 200, no. 3, pp. 774-787, 2010.

[24] C. A. Weber and J. R. Current, "A multiobjective approach to vendor selection," European Journal of Operational Research, vol. 68, no. 2, pp. 173-184, 1993.

[25] J. Xu and L. Yao, Random-Like Multiple Objective Decision Making, Springer, 2011.

[26] J. Xu and X. Zhou, Fuzzy-Like Multiple Objective Decision Making, Springer, Berlin, Germany, 2011.

[27] C.-T. Chen, "A fuzzy approach to select the location of the distribution center," Fuzzy Sets and Systems, vol. 118, no. 1, pp. 65-73, 2001.

[28] D. Petrovic, R. Roy, and R. Petrovic, "Supply chain modelling using fuzzy sets," International Journal of Production Economics, vol. 59, no. 1, pp. 443-453, 1999.

[29] M. Gen and R. Cheng, Genetic Algorithms and Engineering Optimization, John Wiley \& Sons, New York, NY, USA, 2000. 

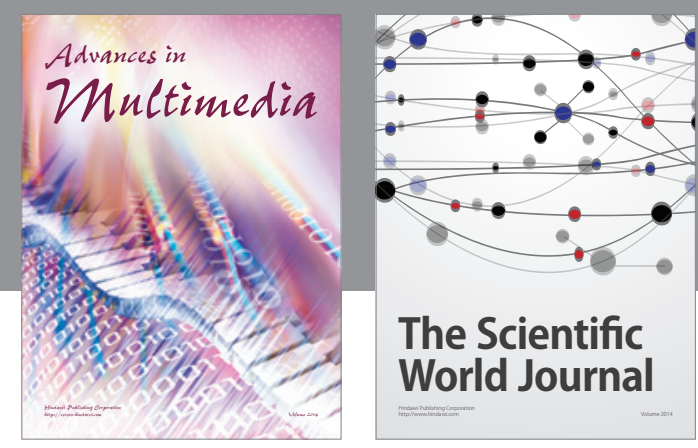

The Scientific World Journal
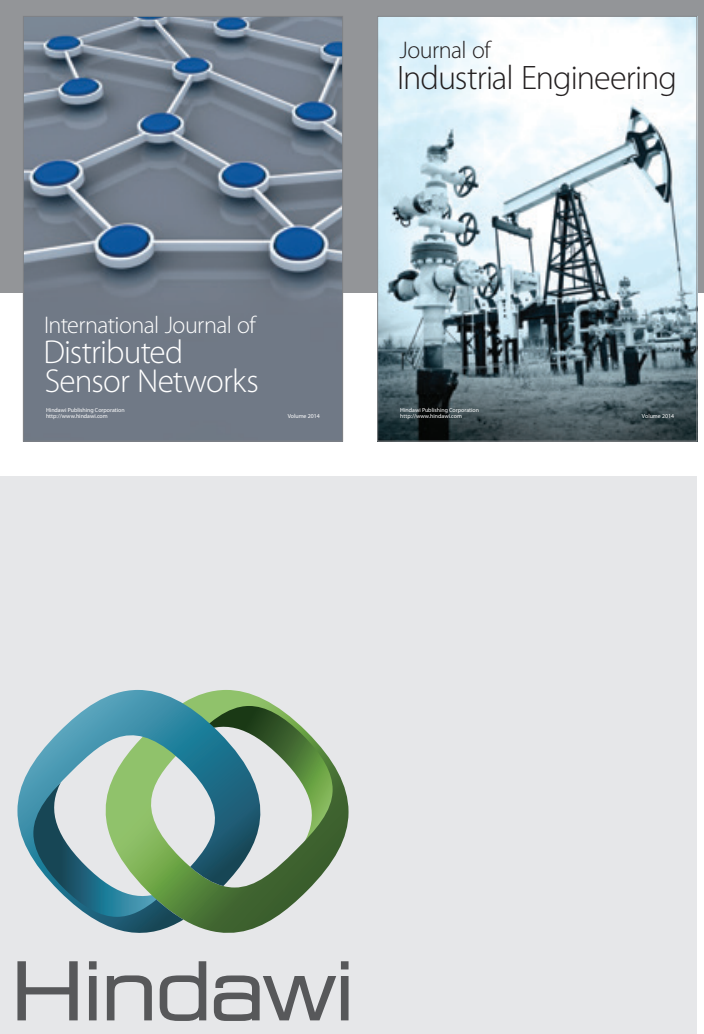

Submit your manuscripts at

http://www.hindawi.com

\section{Computer Networks} and Communications
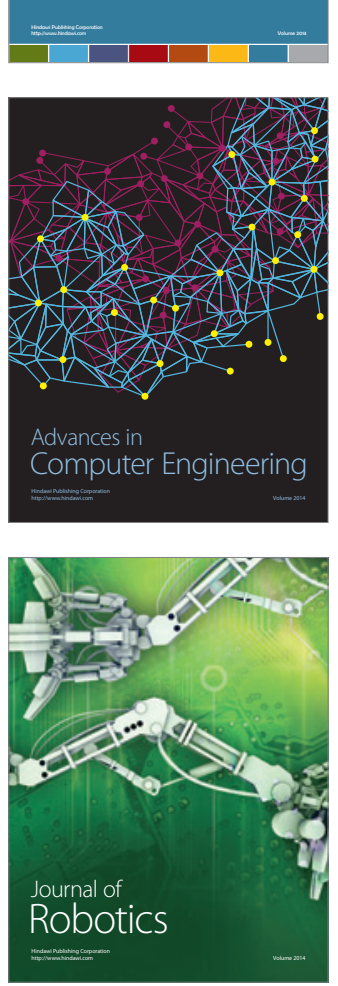
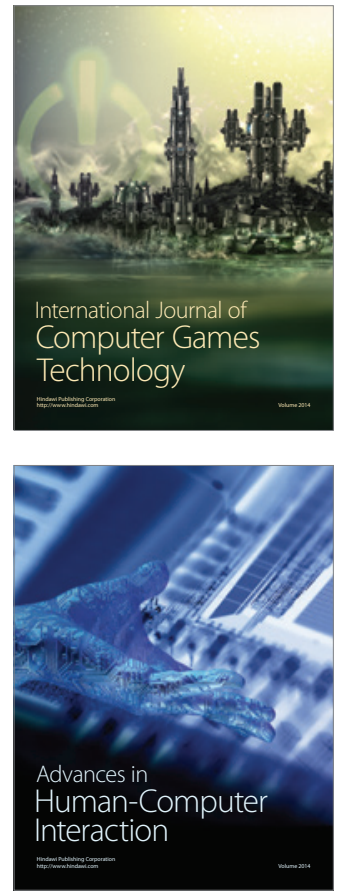
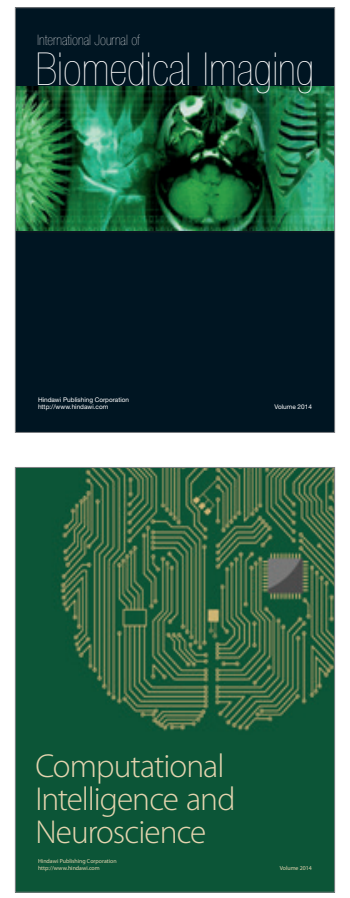
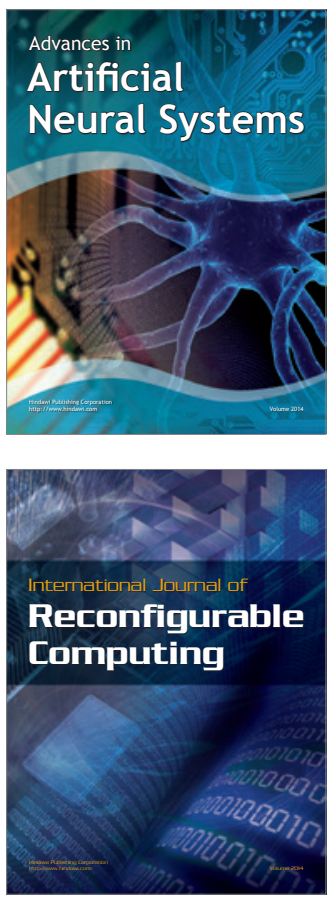
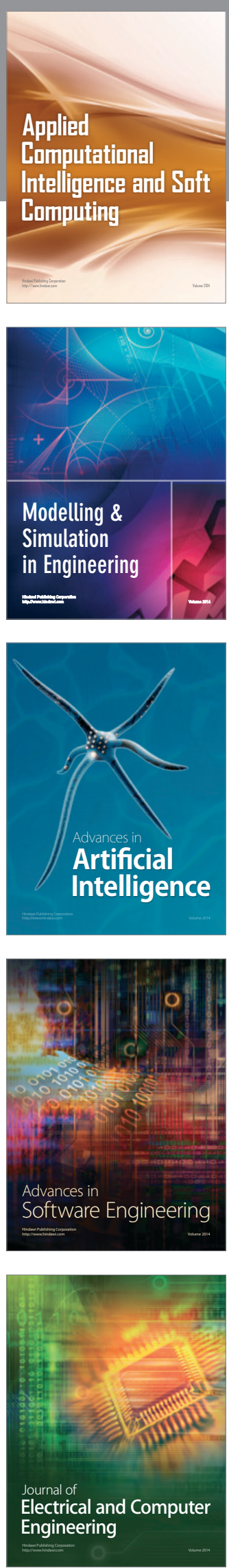